\title{
Експериментальні дослідження впливу взаємозіткнень насіння на їх рух по неперфорованим віброфрикційним площинам
}

\author{
В.М. Лук'яненко ${ }^{1}$, А.О. Никифоров ${ }^{2}$, А.П. Никифорова ${ }^{3}$ \\ Харківський національний технічний університет сільського господарства \\ імені Петра Василенко (м. Харків, Україна), \\ email: 1vmlukyanenko@gmail.com, ${ }^{2}$ toninikiforov89@gmail.com, ${ }^{3}$ petrik.helen@gmail.com \\ ORCID: ${ }^{1}$ 0000-0003-2553-3949, ${ }^{2}$ 0000-0001-7788-8878, ${ }^{3}$ 0000-0002-7966-7777
}

\begin{abstract}
В статті представлені результати експериментальних досліджень впливу взаємозіткнень насіння сільськогосподарських культур на їх рух по робочим площинам віброфрикційної машини. Дослідження проводили на насіннєвих сумішах соняшника і сої, які дуже відрізняються своїми фрізикомеханічними властивостями: фрормою, шорсткістю і пружністю.

Експериментальні дослідження проводилися в трьох існуючих режимах руху насіння по робочим площинам: безвідривному, відривному і ударному. Так як ударний режим руху насіння може забезпечити тільки мехатронна вібраційна мультиплощинна насіннєочисна машина, то така машина і використовувалась в роботі. Робочим органом цієї машини є чотири блоки неперфорованих фррикційних площин (по 25 шт. у кожному блоці), що здійснюють паралельні технологічні процеси сепарації насіннєвих сумішей в трьох режимах руху (безвідривному, відривному і ударному).

В результаті експериментальних досліджень встановлено вплив взаємозіткнень компонентів насіннєвих сумішей між собою на їх рух по сепаруючим площинам вібраційних насіннєочисних машин. Цей вплив істотньо залежить від фрізико-механічних властивостей насіння і їх режиму руху по сепаруючим площинам. Як показали дослідження, найбільш значний вплив взаємозіткнень насіння на його рух спостерігається при безвідривному режимі руху і для насіння плоскої форми 3 найбільш високими показниками шорсткості і незначною пружністю.

За результатами проведених експериментальних досліджень можна зробити висновок про необхідність врахування впливу взаємозіткнень насіння між собою при математичному моделюванні руху насіння по сепаруючим площинах віброфрикційних машин і особливо при вивченні руху плоского, шорсткуватого і непружного насіння у безвідривному режимі руху.
\end{abstract}

Ключові слова: вібрація, мехатронна вібраційна мультиплощинна насіннєочисна машина, насіннєві суміші, сепарація, режим руху насіння, взаємозіткнення насіння.

Вступ. Метод математичного моделювання, що представляє собою кількісний опис досліджуваних явищ за допомогою математичних залежностей, широко застосовується для дослідження всіляких явищ природи.

3 одного боку, працюючи не з самим об'єктом, а з його моделлю, ми можемо відносно швидко і без істотних витрат досліджувати його властивості і поведінку в будь-яких ситуаціях. 3 іншого боку, обчислювальні експерименти з моделями об'єктів дозволяють, спираючись на потужність сучасних обчислювальних методів і обчислювальної техніки, детально і глибоко вивчати об'єкти в достатній повноті, недоступної чисто теоретичним дослідженням (переваги експерименту).

Математичні моделі процесів завжди засновані на деякому спрощенні, ідеалізації, відкиданні факторів, які в даний момент або на даному етапі досліджень представляються несуттєвими.

3 огляду на той фракт, що роль теорії при проектуванні вібраційних насіннєочисних машин надзвичайно велика, математичні моделі динаміки і кінетики насіннєвих сумішей по робочим поверхням вібраційних насіннєочисних машин повинні бути складені при мінімальних припущеннях.

Тому, для розробки нових конструкцій вібраційних насіннєочисних машин, які мали б більш високі показники 3 якості процесу поділу i продуктивності, дуже важливо мати адекватні математичні моделі руху насіннєвих сумішей по робочим поверхням.

Аналіз останніх досліджень і публікацій.

Теорії вібраційного переміщення та сепарації присвячена велика кількість робіт дослідників: 
І.І. Блехмана [1], П.М. Василенка [2], П.М. Заїки [3], Е.Е. Лавендела [4], Д.А. Пліса [5], Г.Д. Терськова [6], В.І. Якубовича [7] та ін., а також зарубіжних авторів: С. Беттхера [8], Р. Вольфштайнера [9], В.Г. Зайделя [10], В. Клокхауза [11], Ф. Радемахера [12], Т. Ріша [13], Р. Юнга [14].

У роботах названих авторів розглядається рух частинок, ідеалізованих, як правило, у вигляді матеріальної точки з певними пружно-фрикційними властивостями в безвідривному режимі руху та в режимі з безперервним підкиданням.

Вивченню вібропереміщення частинок як твердих тіл, що мають різну форму поперечного перерізу, що збігається з площиною коливань: кола, оживала, еліпса, рівнобедреного трикутника, правильного багатокутника, квадрата присвячені роботи [15 - 21]. Геометричний центр поперечного перерізу цих тіл збігається з їх центром тяжіння.

Всі розглянуті вище математичні моделі вібраційного руху частинок по фрикційним поверхням припускають їх вільне переміщення.

Насправді процес вібросепарації істотно відрізняється від моделей вільного переміщення часток. При сепарації на таких робочих органах складові насіннєвих сумішей при русі по різних траєкторіях співударяються і захоплюють одна одну в напрямку, який не відповідає їх вільному переміщенню. У зв'язку з цим, в роботах $[22,23]$ вирішувалося завдання вібраційного переміщення насіннєвого матеріалу з урахуванням взаємодії його компонент.

Мета роботи. Експериментально дослідити рух як окремого насіння так і в якості компоненти різних насіннєвих сумішей по вібруючим неперфорованим поверхням віброфррикційної насіннєочисної машини.

Результати досліджень. Досліджування проводили на робочих поверхнях блочної мехатронної віброфррикційної насіннєочисної машини (рис. 1).

Характерною відмінністю цієї машини від інших зразків вібраційних машин $є$ здатність забезпечувати всі існуючі на теперішній час режими руху насіннєвих сумішей по робочим поверхням: безвідривний, відривний і ударний.

При безвідривному режимі руху насіння весь час має хоч би одну точку контакту з сепаруючою поверхнею. Відривний рух насіння характеризується наявністю моментів часу, коли насіння здійснює вільний політ і в цей час не має контакту з сепаруючою поверхнею. Такий режим руху насіння по сепаруючим поверхням має значно вищу продуктивність.

Ударний режим відрізняється від попередніх ще більшою продуктивністю і характеризується наявністю ударів насіння з нижньою площиною вищерозміщеної сепаруючої пластини. Цей режим руху можливий тільки для блочних машин і потребує більш інтенсивного руху віброзбуджувачів.

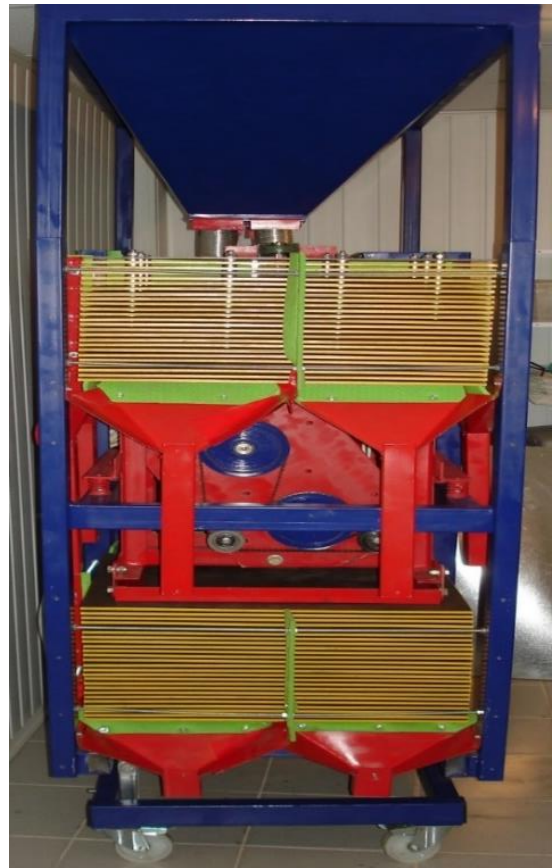

Рис. 1 Загальний вигляд блочної мехатронної вібраційної насіннєочисної машини

Дослідження проводилися з використанням насіннєвих сумішей соняшника і сої. Для цього 3 кожної насіннєвої суміші відбирались 10 насінин і фарбували їх у колір, відмінний від їх природнього (для того, щоб їх було легко відрізнити від основної маси). Дослідження проводили на верхній площині правого верхнього блоку, яка для зручності була проградуйована.

Спочатку брали насіннєву суміш і налаштовували вібраційну насіннєочисну машину на визначений режим руху насіння (безвідривний, відривний або ударний).

Потім на сепаруючу поверхню поміщали одне з відібраних для дослідів пофарбоване насіння i фріксували кут і час його сходження з неї. Після цього пофарбоване насіння змішували з насіннєвою сумішшю і подавали її на сепаруючу поверхню. Відмічали час знаходження фрарбованого насіння на поверхні і кут його сходження з неї.

Результати дослідження насіння соняшника представлені в таблицях 1 - 3.

Проведені експериментальні дослідження впливу взаємозіткнень компонент насіннєвої суміші соняшника на їх рух по неперфорованим вібруючим площинам показали, що відхилення кута сходження досліджуваного насіння при його русі в масі насіння соняшника по відношенню до його вільного руху має найбільше значення при безвідривному режимі руху насіннєвої суміші. Зі збільшенням інтенсивності руху насіння по робочим площинам (відривний і ударний режими руху) вплив взаємозіткнень насіння зменшується.

Час сходження насіння з сепаруючої площини при його русі в масі насіння майже не відрізняється від часу сходження вільного насіння. 
Таблиця 1. Результати дослідження насіння соняшника у безвідривному режимі

\begin{tabular}{|c|c|c|c|c|c|c|c|c|c|c|c|}
\hline \multicolumn{12}{|c|}{ БЕЗВІДРИВНИЙ РУХ } \\
\hline \multicolumn{5}{|c|}{ Подовжній кут нахилу поверхні - 5,50 } & \multicolumn{7}{|c|}{ Поперечний кут нахилу поверхні - 3,50 } \\
\hline \multicolumn{5}{|c|}{ Частота коливань - 1345 об/хв. } & \multicolumn{7}{|c|}{ Амплітуда коливань - 1,6 мм. } \\
\hline \multicolumn{12}{|c|}{ Продуктивність однієї сепаруючої поверхні - 4 кг/год. } \\
\hline \multirow{2}{*}{ Показник } & \multicolumn{10}{|c|}{ Насіння соняшника } & \multirow{2}{*}{$\begin{array}{c}\text { Середнє } \\
\text { значення } \\
\text { показника }\end{array}$} \\
\hline & 1 & 2 & 3 & 4 & 5 & 6 & 7 & 8 & 9 & 10 & \\
\hline $\begin{array}{l}\text { Кут сходження вільного насіння } 3 \\
\text { сепаруючої площини, град }\end{array}$ & 95 & 135 & 60 & 60 & 95 & 115 & 80 & 53 & 80 & 115 & \\
\hline $\begin{array}{l}\text { Кут сходження насіння з сепаруючої } \\
\text { площини (при його русі в масі насіння), град }\end{array}$ & 85 & 133 & 65 & 55 & 85 & 100 & 110 & 110 & 85 & 100 & \\
\hline Відхилення, \% & 11 & 1 & 8 & 8 & 11 & 4 & 38 & 108 & 6 & 13 & 21 \\
\hline $\begin{array}{l}\text { Час сходження вільного насіння } 3 \\
\text { сепаруючої площини, с }\end{array}$ & 30 & 16 & 35 & 43 & 31 & 35 & 41 & 40 & 40 & 32 & 34 \\
\hline $\begin{array}{l}\text { Час сходження насіння з сепаруючої } \\
\text { площини (при його русі в масі насіння), с }\end{array}$ & 30 & 17 & 38 & 35 & 30 & 44 & 34 & 34 & 34 & 30 & 33 \\
\hline
\end{tabular}

Таблиця 2. Результати дослідження насіння соняшника у відривному режимі

\begin{tabular}{|c|c|c|c|c|c|c|c|c|c|c|c|}
\hline \multicolumn{12}{|c|}{ ВІДРИВНИЙ РУХ } \\
\hline \multicolumn{5}{|c|}{ Подовжній кут нахилу поверхні - 4,30 } & \multicolumn{7}{|c|}{ Поперечний кут нахилу поверхні - 3,50 } \\
\hline \multicolumn{5}{|c|}{ Частота коливань - 1750 об/хв. } & \multicolumn{7}{|c|}{ Амплітуда коливань - 2,4 мм. } \\
\hline \multicolumn{12}{|c|}{ Продуктивність однієї сепаруючої поверхні - 9,6 кг/год. } \\
\hline \multirow{2}{*}{ Показник } & \multicolumn{10}{|c|}{ Насіння соняшника } & \multirow{2}{*}{$\begin{array}{c}\text { Середнє } \\
\text { значення } \\
\text { показника }\end{array}$} \\
\hline & 1 & 2 & 3 & 4 & 5 & 6 & 7 & 8 & 9 & 10 & \\
\hline $\begin{array}{l}\text { Кут сходження вільного насіння } 3 \\
\text { сепаруючої площини, град }\end{array}$ & 110 & 113 & 95 & 105 & 97 & 105 & 90 & 113 & 113 & 100 & \\
\hline $\begin{array}{l}\text { Кут сходження насіння з сепаруючої } \\
\text { площини (при його русі в масі насіння), град }\end{array}$ & 100 & 95 & 97 & 100 & 93 & 120 & 100 & 100 & 105 & 78 & \\
\hline Відхилення, \% & 9 & 16 & 2 & 5 & 4 & 14 & 11 & 12 & 7 & 22 & 10 \\
\hline $\begin{array}{l}\text { Час сходження вільного насіння } 3 \\
\text { сепаруючої площини, с }\end{array}$ & 7 & 8 & 7 & 13 & 7 & 9 & 8 & 12 & 7 & 7 & 9 \\
\hline $\begin{array}{l}\text { Час сходження насіння з сепаруючої } \\
\text { площини (при його русі в масі насіння), с }\end{array}$ & 12 & 9 & 7 & 7 & 8 & 7 & 9 & 13 & 10 & 12 & 9 \\
\hline
\end{tabular}

Таблиця 3. Результати дослідження насіння соняшника в ударному режимі

\begin{tabular}{|c|c|c|c|c|c|c|c|c|c|c|c|}
\hline \multicolumn{12}{|c|}{ УДАРНИЙ РУХ } \\
\hline \multicolumn{5}{|c|}{ Подовжній кут нахилу поверхні - 3,50 } & \multicolumn{7}{|c|}{ Поперечний кут нахилу поверхні - 3,50 } \\
\hline \multicolumn{5}{|c|}{ Частота коливань - 2095 об/хв. } & \multicolumn{7}{|c|}{ Амплітуда коливань - 3,2 мм. } \\
\hline \multicolumn{12}{|c|}{ Продуктивність однієї сепаруючої поверхні - 15 кг/год. } \\
\hline \multirow{2}{*}{ Показник } & \multicolumn{10}{|c|}{ Насіння соняшника } & \multirow{2}{*}{$\begin{array}{c}\text { Середнє } \\
\text { значення } \\
\text { показника }\end{array}$} \\
\hline & 1 & 2 & 3 & 4 & 5 & 6 & 7 & 8 & 9 & 10 & \\
\hline $\begin{array}{l}\text { Кут сходження вільного насіння } 3 \\
\text { сепаруючої площини, град }\end{array}$ & 78 & 85 & 80 & 90 & 90 & 72 & 88 & 94 & 84 & 78 & \\
\hline $\begin{array}{l}\text { Кут сходження насіння з сепаруючої } \\
\text { площини (при його русі в масі насіння), град }\end{array}$ & 58 & 82 & 80 & 95 & 85 & 80 & 70 & 80 & 80 & 75 & \\
\hline Відхилення, \% & 26 & 4 & 0 & 6 & 6 & 11 & 20 & 15 & 5 & 4 & 8 \\
\hline $\begin{array}{l}\text { Час сходження вільного насіння з } \\
\text { сепаруючої площини, с }\end{array}$ & 7 & 12 & 7 & 10 & 9 & 11 & 16 & 8 & 13 & 8 & 10 \\
\hline $\begin{array}{l}\text { Час сходження насіння з сепаруючої } \\
\text { площини (при його русі в масі насіння), с }\end{array}$ & 9 & 10 & 10 & 10 & 8 & 9 & 11 & 10 & 15 & 13 & 11 \\
\hline
\end{tabular}


Таблиця 4. Результати дослідження насіння сої у безвідривному режимі

\begin{tabular}{|c|c|c|c|c|c|c|c|c|c|c|c|}
\hline \multicolumn{12}{|c|}{ БЕЗВІДРИВНИЙ РУХ } \\
\hline \multicolumn{5}{|c|}{ Подовжній кут нахилу поверхні - 4,00 } & \multicolumn{7}{|c|}{ Поперечний кут нахилу поверхні - 3,50 } \\
\hline \multicolumn{5}{|c|}{ Частота коливань - 1294 об/хв. } & \multicolumn{7}{|c|}{ Амплітуда коливань - 1,4 мм. } \\
\hline \multicolumn{12}{|c|}{ Продуктивність однієї сепаруючої поверхні - 8,6 кг/год. } \\
\hline \multirow{2}{*}{ Показник } & \multicolumn{10}{|c|}{ Насіння соняшника } & \multirow{2}{*}{$\begin{array}{c}\text { Середнє } \\
\text { значення } \\
\text { показника }\end{array}$} \\
\hline & 1 & 2 & 3 & 4 & 5 & 6 & 7 & 8 & 9 & 10 & \\
\hline $\begin{array}{l}\text { Кут сходження вільного насіння } 3 \\
\text { сепаруючої площини, град }\end{array}$ & 20 & 55 & 20 & 110 & 95 & 45 & 75 & 35 & 100 & 85 & \\
\hline $\begin{array}{l}\text { Кут сходження насіння з сепаруючої } \\
\text { площини (при його русі в масі насіння), град }\end{array}$ & 115 & 70 & 130 & 125 & 115 & 40 & 125 & 70 & 145 & 125 & \\
\hline Відхилення, \% & 475 & 27 & 550 & 14 & 21 & 11 & 67 & 100 & 45 & 47 & 136 \\
\hline $\begin{array}{l}\text { Час сходження вільного насіння } 3 \\
\text { сепаруючої площини, с }\end{array}$ & 3 & 4 & 6 & 20 & 10 & 11 & 9 & 4 & 14 & 3 & 11 \\
\hline $\begin{array}{l}\text { Час сходження насіння з сепаруючої } \\
\text { площини (при його русі в масі насіння), с }\end{array}$ & 17 & 4 & 5 & 25 & 11 & 6 & 25 & 11 & 5 & 25 & 13 \\
\hline
\end{tabular}

Таблиця 5. Результати дослідження насіння сої у відривному режимі

\begin{tabular}{|c|c|c|c|c|c|c|c|c|c|c|c|}
\hline \multicolumn{12}{|c|}{ ВІДРИВНИЙ РУХ } \\
\hline \multicolumn{5}{|c|}{ Подовжній кут нахилу поверхні - 2,50 } & \multicolumn{7}{|c|}{ Поперечний кут нахилу поверхні - 3,50 } \\
\hline \multicolumn{5}{|c|}{ Частота коливань - 1645 об/хв. } & \multicolumn{7}{|c|}{ Амплітуда коливань - 2,2 мм. } \\
\hline \multicolumn{12}{|c|}{ Продуктивність однієї сепаруючої поверхні - 12,4 кг/год. } \\
\hline \multirow{2}{*}{ Показник } & \multicolumn{10}{|c|}{ Насіння сої } & \multirow{2}{*}{$\begin{array}{c}\text { Середнє } \\
\text { значення } \\
\text { показника }\end{array}$} \\
\hline & 1 & 2 & 3 & 4 & 5 & 6 & 7 & 8 & 9 & 10 & \\
\hline $\begin{array}{l}\text { Кут сходження вільного насіння } 3 \\
\text { сепаруючої площини, град }\end{array}$ & 110 & 165 & 145 & 155 & 120 & 100 & 120 & 120 & 75 & 137 & \\
\hline $\begin{array}{l}\text { Кут сходження насіння з сепаруючої } \\
\text { площини (при його русі в масі насіння), град }\end{array}$ & 97 & 140 & 100 & 120 & 85 & 115 & 105 & 82 & 85 & 150 & \\
\hline Відхилення, \% & 12 & 15 & 31 & 23 & 29 & 15 & 13 & 32 & 13 & 9 & 19 \\
\hline $\begin{array}{l}\text { Час сходження вільного насіння } 3 \\
\text { сепаруючої площини, с }\end{array}$ & 7 & 5 & 4 & 8 & 11 & 11 & 12 & 12 & 13 & 7 & 9 \\
\hline $\begin{array}{l}\text { Час сходження насіння з сепаруючої } \\
\text { площини (при його русі в масі насіння), с }\end{array}$ & 12 & 4 & 5 & 10 & 8 & 12 & 11 & 10 & 11 & 6 & 9 \\
\hline
\end{tabular}

Таблиця 6. Результати дослідження насіння сої в ударному режимі

\begin{tabular}{|c|c|c|c|c|c|c|c|c|c|c|c|}
\hline \multicolumn{12}{|c|}{ УДАРНИЙ РУХ } \\
\hline \multicolumn{5}{|c|}{ Подовжній кут нахилу поверхні - $1,5^{0}$} & \multicolumn{7}{|c|}{ Поперечний кут нахилу поверхні - 3,50 } \\
\hline \multicolumn{5}{|c|}{ Частота коливань - 1980 об/хв. } & \multicolumn{7}{|c|}{ Амплітуда коливань - 3,5 мм. } \\
\hline \multicolumn{12}{|c|}{ Продуктивність однієї сепаруючої поверхні - 18,3 кг/год. } \\
\hline \multirow{2}{*}{ Показник } & \multicolumn{10}{|c|}{ Насіння сої } & \multirow{2}{*}{$\begin{array}{c}\text { Середнє } \\
\text { значення } \\
\text { показника }\end{array}$} \\
\hline & 1 & 2 & 3 & 4 & 5 & 6 & 7 & 8 & 9 & 10 & \\
\hline $\begin{array}{l}\text { Кут сходження вільного насіння з } \\
\text { сепаруючої площини, град }\end{array}$ & 80 & 84 & 90 & 70 & 110 & 80 & 80 & 80 & 70 & 90 & \\
\hline $\begin{array}{l}\text { Кут сходження насіння з сепаруючої } \\
\text { площини (при його русі в масі насіння), град }\end{array}$ & 85 & 90 & 81 & 95 & 70 & 83 & 85 & 78 & 110 & 85 & \\
\hline Відхилення, \% & 6 & 7 & 10 & 36 & 36 & 4 & 6 & 3 & 57 & 6 & 17 \\
\hline $\begin{array}{l}\text { Час сходження вільного насіння з } \\
\text { сепаруючої площини, с }\end{array}$ & 35 & 11 & 27 & 15 & 16 & 38 & 12 & 20 & 15 & 9 & 20 \\
\hline $\begin{array}{l}\text { Час сходження насіння з сепаруючої } \\
\text { площини (при його русі в масі насіння), с }\end{array}$ & 20 & 7 & 13 & 10 & 12 & 15 & 15 & 13 & 8 & 5 & 12 \\
\hline
\end{tabular}


Дослідження впливу взаємозіткнень насіння сої на їх рух по сепаруючим пластинам віброфррикційної насіннєочисної машини показали, що відхилення кута сходження насіння сої при його русі в масі насіння по відношенню до вільного його руху становить у безвідривному режимі руху $136 \%$. При використанні відривного і ударного режимів руху насіння цей показник становить 19 i 17\% відповідно.

Висновки. За результатами проведених експериментальних досліджень можна зробити наступні висновки:

- взаємозіткнення компонентів насіннєвих сумішей між собою впливають на рух насіння по сепаруючим площинам вібраційних машин;

- вплив взаємозіткнень насіння залежить від фрізико-механічних властивостей насіння і режиму руху його по сепаруючим площинам;

максимальний вплив взаємозіткнень насіння на його рух спостерігається при безвідривному режимі руху плоского і непружного насіння.

\section{Література:}

1. Блехман И.И. Вибрационная механика / И.И. Блехман. - М.: Физматлит, 1994. - 400 с.

2. Василенко П.М. Теория движения частиц по шероховатым поверхностям сельскохозяйственных машин / П.М. Василенко. - К.: УАСХН, 1960. - 284 c.

3. Заика П.М. Динамика вибрационных зерноочистительных машин / П.М. Заика. - М.: Машиностроение, 1977. - 276 с.

4. Лавендел Э.Э. Синтез оптимальных вибромашин / Э.Э. Лавендел. - Рига: Зинатне, 1970. -252 c.

5. Плисс Д.А. К теории вибрационной сепарации / Д.А. Плисс // Изв. АН СССР. Механика твердого тела. - 1967. - № 4. - С. 25 - 31.

6. Терсков Г.Д. Расчет зерноуборочных машин / Г.Д. Терсков. - Свердловск: Гостехиздат, 1949. -206 с.

7. Якубович В.И. Некоторые вопросы теории виброперемещения и сепарирования при эллиптических колебаниях / В.И. Якубович. - М.: Наука, 1973. $-80 \mathrm{c}$.

8. Böttcher S. Beitrag zur Klärung der Gutbewegung auf Schwingrinnen: Diss. zur Erlangung des akademischen Grades Doktoringenieur. Technische Hochschule Hannover / S. Böttcher. - Hannover, 1957. - 115 p.

9. Wolfsteiner P. Dynamik von Vibrationsförderern / P. Wolfsteiner. - Düsseldorf: VDI-Verlag, 1999. - $122 \mathrm{p}$.

10. Seidel H. Die Wurfbewegung von Schüttgut auf der schwingenden Ebene / $\mathrm{H}$. Seidel // Bergbautechnik. - 1958. - № 8. - P. $23-31$.

11. Klockhaus W. Fördergeschwindigkeit von Schwingrinnen und Schwindsieben / W. Klockhaus / /Erdöl und Kohle. - 1952. - № 5. - P. 493 - 495.
12. Rademacher F. On the theoretical and experimental conveying speed of granular bulk solids on vibratory conveyors / F. Rademacher, L. Borg // Forschung im Ingenieurwesen. - 1994. - Vol. 60 (10). - P. $261-283$.

13. Risch T. Zweidimensionale Bewegungsformen in der Vibrationsfördertechnik: Diss. zur Erlangung des akademischen Grades Doktoringenieur. Technischen Universität Chemnitz / T. Risch. - Chemnitz, 2010. - 155 p.

14. Jung R. Die Gleitbewegung auf der schwingenden Ebene / R. Jung // Forschung auf dem Gebiete des Ingenieurwesens. - 1952. - Vol. 18. - P. $13-24$.

15. Заика П.М., Ильин В.Я., Сметанкин В.А. Плоскопаралельное движение эллипса по вибрирующей плоскости // Применение новейших математических методов и вычислительной техники в решении инженерных задач: Сб. научн. тр. МИИСП. Т. 13, вып. 10. -М., 1979. - С. 3-8.

16. Бакеев С.Д. Обоснование оптимальных параметров вибросепарации семян сельскохозяйственных культур с учетом их формы на неперфорированных фрикционных поверхностях: автореф. дис. на соиск. степени канд. техн. наук /С.Д. Бакеев.- Харьков, 1987. - 20 с.

17. Гридякин В.А. Обоснование параметров технологического процесса очистки семян кенафа на вибрационной семеочистительной машине: автореф. дис. на соиск. степени канд. техн. наук /В.А. Гридякин.-Харьков, 1989. - 20 с.

18. Козій О.Б. Обгрунтування параметрів технологічного процесу очищення і сортування насіння зернових культур на вібраційній насіннєочисній машині: автореф. дис. на здобуття. ступеня канд. техн. наук /О.Б. Козій. -Харків, 1998. -17 с.

19. Жмай Л.Г. Обоснование параметров технологического процесса очистки и сортирования семян овощных культур на вибрационной семеочистительной машине: автореф. дис. на соиск. степени канд. техн. наук / Л.Г. Жмай.- Харьков, 1990. -24 с.

20. Лук'яненко В.М. Обгрунтування параметрів процесу сепарації насіння ріпака і суріпиці на вібраційній машині: автореф. дис. на здобуття ступеня канд. техн. наук / В.М. Лук'яненко.- Харків, 2001. -20 c.

21. Богомолов А.В. Обоснование параметров технологического процесса очистки и сортирования семян конопли на вибрационной семеочистительной машине: автореф. дис. на соиск. степени канд. техн. наук / А.В. Богомолов.- Харьков, 1984. $-21 \mathrm{c}$.

22. Заика П.М., Слоновский Н.В., Ильин В.Я. Исследование процесса сепарации семян с учетом их взаимного влияния при движении по рабочей поверхности сепаратора//Динамические процессы и надежность машин: Сб. научн. тр. МИИСП. Т. 14, вып. 12. -М., 1977. - 9 с. 
23. Антонов Е.Е. Обоснование оптимальных параметров процесса сепарации семян цветочных культур с учетом их взаимодействия на вибрационных неперфорированных поверхностях: автореф. дис. на соиск. степени канд. техн. наук / Е.Е. Антонов. - Харьков, 1988. - 20 с.

\section{References:}

1. Blehman, I., (1994). Vibracionnaya Mehanika. Moskva: Fizmatlit, p.400.

2. Vasilenko, P., (1960). Teoriya dvizheniya chastic po sherohovatym poverhnostyam selskohozyaj-stvennyh mashin. K:UASHN, p.284.

3. Zaika, P., (1977). Dinamika vibracionnyh zernoochistitelnyh mashin. M.: Mashinostroenie, p.276.

4. Lavendel, E., (1970). Sintez optimalnyh vibromashin. Riga: Zinatne, p.252.

5. Pliss, D., (1967). K teorii vibracionnoj separacii. Izv. AN SSSR. Mehanika tverdogo tela, № 4, pp.25-31.

6. Terskov, G., (1949). Raschet zernouborochnyh mashin. Sverdlovsk: Gostehizdat, p.206.

7. Yakubovich, V., (1973). Nekotorye voprosy teorii vibroperemesheniya i separirovaniya pri ellipticheskih kolebaniyah. M.: Nauka, p.80.

8. Böttcher, S., (1957). Beitrag zur Klärung der Gutbewegung auf Schwingrinnen: Diss. zur Erlangung des akademischen Grades Doktoringenieur. Technische Hochschule Hannover / S. Böttcher. - Hannover, p.115.

9. Wolfsteiner, P., (1999). Dynamik von Vibrationsförderern. Düsseldorf: VDI-Verlag, p.122.

10. Seidel, H., (1958). Die Wurfbewegung von Schüttgut auf der schwingenden Ebene. Bergbautechnik, (№ 8), pp.23-31.

11. Klockhaus, W., (1952). Fördergeschwindigkeit von Schwingrinnen und Schwindsieben. Erdöl und Kohle, (5), pp.493-495.

12. Rademacher, F. and Borg, L., (1994). On the theoretical and experimental conveying speed of granular bulk solids on vibratory conveyors. Forschung im Ingenieurwesen, (60 (10)), pp.261-283.

13. Risch, T., (2010). Zweidimensionale Bewegungsformen in der Vibrationsfördertechnik. Diss. zur Erlangung des akademischen Grades Doktoringenieur. Technischen Universität Chemnitz, p.155.
14. Jung, R., (1952). Die Gleitbewegung auf der schwingenden Ebene. Forschung auf dem Gebiete des Ingenieurwesens, 18, pp.13-24.

15. Zaika, P., Ilin, V. and Smetankin, V., (1979). Ploskoparalelnoe dvizhenie ellipsa po vibriruyushej ploskosti. Primenenie novejshih matematicheskih metodov $i$ vychislitelnoj tehniki $v$ reshenii inzhenernyh zadach: Sb. nauchn. tr. MIISP., (13(10)), pp.3-8.

16. Bakeev S., (1987). Obosnovanie optimalnyh parametrov vibroseparacii semyan selskoho-zyajstvennyh kultur s uchetom ih formy na ne-perforirovannyh frikcionnyh poverhnostyah. Avtoref. dis. na soisk. stepeni kand. tehn, Harkov, p 20 s.

17. Gridyakin V. (1989). Obosnovanie parametrov tehnologicheskogo processa ochistki semyan ke-nafa na vibracionnoj semeochistitelnoj mashine. Avtoref. dis. na soisk. stepeni kand. tehn. nauk. Harkov, p 20.

18. Kozij O. (1998). Obgruntuvannya parametriv tehnologichnogo procesu ochishennya i sortuvannya nasinnya zernovih kultur na vibracijnij nasinnyeochisnij mashini. Avtoref. dis. na zdobut-tya. stupenya kand. tehn. nauk, Harkiv,p 17.

19. Zhmaj L. (1990). Obosnovanie parametrov tehnologicheskogo processa ochistki i sortiro-vaniya semyan ovoshnyh kultur na vibracionnoj semeochistitelnoj mashine. Avtoref. dis. na soisk. stepeni kand. tehn. nauk, Harkov, p 24.

20. Luk'yanenko V. (2001). Obgruntuvannya para-metriv procesu separaciyi nasinnya ripaka i suripici na vibracijnij mashini. Avtoref. dis. na zdobuttya stupenya kand. tehn. nauk, Harkiv, p 20.

21. Bogomolov A. (1984). Obosnovanie paramet-rov tehnologicheskogo processa ochistki i sortirovaniya semyan konopli na vibracionnoj semeochistitelnoj mashine. Avtoref. dis. na soisk. stepeni kand. tehn, Harkov p 21.

22. Zaika P., Slonovskij N. and Ilin V. (1977). Issledovanie processa separacii semyan $s$ uchetom in vzaimnogo vliyaniya pri dvizhenii po rabochej poverhnosti separatora. Dinamicheskie processy i nadezhnost mashin: Sb. nauchn. tr. MIISP, (14(12)), p 9 .

23. Antonov E. (1988). Obosnovanie optimalnyh parametrov processa separacii semyan cvetoch-nyh kultur s uchetom ih vzaimodejstviya na vibracionnyh neperforirovannyh poverhno-styah. Avtoref. dis. na soisk. stepeni kand. tehn. nauk, Harkov, p20.

\title{
Аннотация
}

\section{Экспериментальные исследования влияния взаимостолкновений семян на их движение по неперфорированным виброфрикционным плоскостям}

\author{
В.М. Лукьяненко, А.О.Никифоров, А.П. Никифорова
}

В статье представлены результаты экспериментальных исследований влияния взаимостолкновений семян сельскохозяйственных культур на их движение по рабочим плоскостям виброфрикционной машины. Исследования проводились на семенных смесях подсолнечника и сои, которые очень отличаются своими физико-механическими свойствами: формой, шероховатостью и упругостью.

Экспериментальные исследования проводились в трех существующих режимах движения семян по рабочим плоскостям: безотрывном, отрывном и ударном. Так как ударный режим движения семян 
может обеспечить только мехатронная вибрационная мультиплоскостная семяочистительная машина, то такая машина и использовалась в работе. Рабочим органом этой машины есть четыре блока неперфорированных фрикционных плоскостей (по 25 шт. в каждом блоке), осуществляющих параллельные технологические процессы сепарации семенных смесей в трех режимах движения (безотрывном, отрывном и ударном).

В результате экспериментальных исследований установлено влияние взаимостолкновений компонентов семенных смесей между собой на их движение по сепарирующим плоскостям вибрационных семяочистительных машин. Это влияние существенно зависит от физико-механических свойств семян и их режима движения по сепарирующим плоскостям. Как показали исследования, наиболее значительное влияние взаимостолкновений семян на его движение наблюдается при безотрывном режиме движения и для семян плоской формы с наиболее высокими показателями шероховатости и незначительной упругости.

По результатам проведенных экспериментальных исследований можно сделать вывод о необходимости учета влияния взаимостолкновений семян между собой при математическом моделировании движения семян по сепарирующим плоскостям виброфрикцийних машин и особенно при изучении движения плоских, шероховатых и неупругих семян в безотрывном режиме движения.

Ключевые слова: вибрация, мехатронная вибрационная мультиплоскостная семяочистительная машина, семенные смеси, сепарация, режим движения семян, взаимостолкновение семян.

\section{Abstract \\ Experimental research influences of seeds on the movement of the seeds on their non-perforated vibration frictions}

\section{V.M. Lukyanenko, A.A. Nykyforov, A.P. Nykyforova}

The article presents the results of experimental studies of the effect of crop seed interplants on their movement on the working plane of a vibration friction machine. The studies were performed on seed mixtures of sunflower and soybeans, which are very different in their physical and mechanical properties: shape, roughness and elasticity.

Experimental studies were conducted in three existing modes of movement of seeds on the working plane: inseparable, tear-off and shock. Since the shock mode of movement of seeds can only provide mechatronic vibrating multi-plane seed cleaning machine, this machine was used in the work. The working body of this machine are four blocks of non-perforated friction planes ( 25 pieces in each block), which carry out parallel technological processes of separation of seed mixtures in three modes of movement (inseparable, tear-off and shock).

As a result of the experimental studies, the effect of the interconnections of the components of the seed mixtures with each other on their movement along the separating planes of the vibrating seed-cleaning machines has been established. This influence is significantly dependent on the physical and mechanical properties of the seeds and their mode of motion on the separating planes. Studies have shown that the most significant effect of seed interference on its movement is observed in a continuous mode of movement and for seeds of flat shape with the highest roughness and low elasticity.

According to the results of the experimental studies, it is possible to conclude the need to take into account the influence of seed interconnections with each other in mathematical modelling of seed movement on the separating planes of vibrating friction machines and especially in the study of the motion of flat, rough and inelastic seeds in a continuous motion.

Keywords: vibration, mechatronic vibrating multi-plane seed cleaning machine, seed mixtures, separation, mode of movement of seeds, mutual contact of seeds.

\section{Бібліографічне посилання/ Bibliography citation: Harvard}

Lukyanenko, V. M., Nykyforov, A. A. and Nykyforova, A. P. (2020) 'Experimental research influences of seeds on the movement of the seeds on their non-perforated vibration frictions'. Engineering of nature management, (2(16), pp. $53-59$.

Подано до редакції / Received: 21.08.2020

ISSN 2311-1828

http://enm.khntusg.com.ua
Інженерія природокористування, 2020, №2(16), с. 53 - 59

Engineering of nature management, 2020, \#2(16), p. 53 - 59 